\title{
The Decision-Makers' Forum on a New Paradigm for Nuclear Energy
}

September 14, 1998

FINAL REPORT 


\section{Contents}

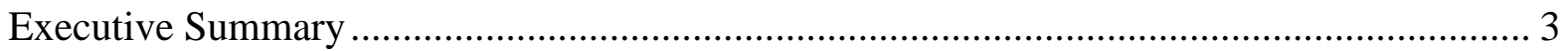

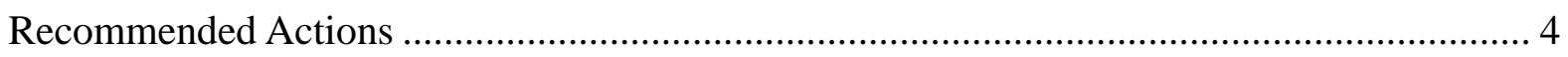

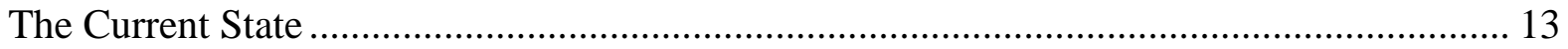

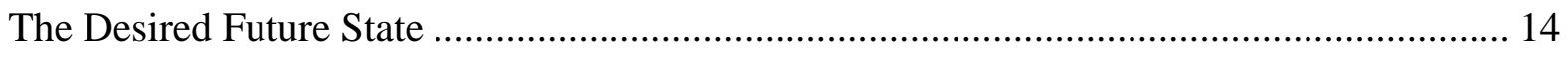

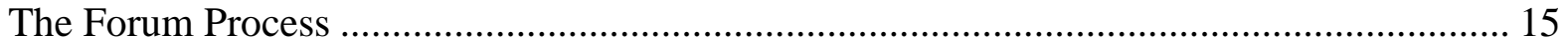

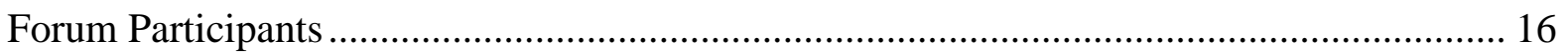




\section{Disclaimer}

Neither the U.S. Government nor any agency thereof, nor any of their employees, makes any warranty, express of implied, or assumes any legal liability or responsibility for the accuracy, completeness, or usefulness of any information, apparatus, product, or process disclosed, or represents that its use would not infringe privately owned rights. References herein to any specific commercial product, process, or service by trade name, trademark, manufacturer, or otherwise, does not necessarily constitute or imply its endorsement, recommendation or favoring by the U.S. Government or any agency thereof. The views and opinions of authors expressed herein do not necessarily state or reflect those of the U.S. Government or any agency thereof. Further, the views and opinions expressed herein do not necessarily state or reflect the policy of the U.S. Department of Energy or the Idaho National Engineering and Environmental Laboratory. Rather, the views and opinions expressed herein are intended to faithfully represent the recommendations from the independent body collectively known as the Decision Makers' Forum participants. 


\section{The Decision-Makers' Forum on a New Paradigm for Nuclear Energy}

\section{EXECUTIVE SUMMARY}

The Decision-Makers' Forum on a New Paradigm for Nuclear Energy was held on June 19, 1998 in Washington DC. The Forum was created as a response to the recent challenge by Sen. Pete V. Domenici to begin, "a new dialogue with serious discussion about the full range of nuclear technologies." Sponsored by the Senate Nuclear Issues Caucus, the Forum was organized and facilitated by the Idaho National Engineering and Environmental Laboratory. About 60 people participated in the Forum. The participants were decision-makers and key staff from industry, government, the national laboratories, academia and professional societies.

The Forum featured a high-level facilitated discussion on how to build a new paradigm for nuclear energy. The Forum produced about 100 pages of ideas, comments and tabulations of votes on various ideas for action captured in the Forum Record. From this the editorial team consolidated a set of ten priority actions from the Forum and wrote descriptions of the actions to reflect the perspectives and comments of the participants.

Overall, the Forum was designed to capture the ideas of a large number of decision-makers about the high priority actions recommended to help set a new national agenda for nuclear energy. The Forum recommends the following priority actions toward this end:

1. The Department of Energy should create a broad-based nuclear mission that advocates a viable commercial sector, produces topquality scientists and engineers, develops options and techniques for disposal and recycle, and funds reactor and fuel cycle research and development as an integrated component of an overall energy portfolio.
2. Congress should direct and immediately fund the construction of a monitored retrievable spent fuel storage facility.

3. Congress should support a comprehensive program to secure all weapons grade plutonium and highly enriched uranium, to expand the purchase of vulnerable highly enriched uranium and to undertake a Russian "nuclear cities" initiative.

4. Congress should direct that the nuclear regulatory process be reformed to produce a more efficient, less costly, risk- and performancebased regulatory oversight process.

5. The Department of Energy should study the full-cycle economic and environmental costs of energy options, and Congress should legislate a level playing field for all energy sources, including nuclear energy.

6. Congress and the Administration should increase the budget of the Nuclear Energy Research Initiative (NERI) and Nuclear Energy Plant Optimization (NEPO) programs, and the Department of Energy should provide sharper focus to the NERI program.

7. The Department of Energy should create and fund a viable international reactor technology development program that reduces the threat from weapons plutonium and also encourages the use of new and existing reactors to burn weapons plutonium.

8. The Department of Energy should increase public understanding of energy production and nuclear technology.

9. Congress should fund increased research to resolve the health issues of low level radiation exposure to humans.

10. Congress should consider establishing a joint committee on nuclear energy. 


\section{RECOMMENDED ACTIONS}

\section{Action 1}

The Department of Energy should create a broad-based nuclear mission that advocates a viable commercial sector, produces top-quality scientists and engineers, develops options and techniques for disposal and recycle, and funds reactor and fuel cycle research and development as an integrated component of an overall energy portfolio.

Three major problems were identified which limit the Department of Energy from achieving its strategic goal of promoting energy systems, especially with regard to nuclear energy. First, the current policy on advanced systems for nuclear power and sustainable fuel cycles is a barrier to the development of nuclear energy and must be changed. Second, the Department's leadership and advocacy of nuclear power has become weak and must be greatly strengthened. Third, there is a lack of long-term stability and expertise within the Department's executive management, programs and career staff which needs to be bolstered.

The Forum proposes that these problems could be addressed by creating a broad-based nuclear energy mission within the Department that is defined in detail, and has an effective strategy and the resources necessary to conduct it. A new definition of the mission is needed. Such a mission must cut across the Department's four business lines: energy resources, environmental quality, national security, and science and technology. The rejection of its current policy against advanced systems and fuel cycles and an integrated approach to the mission would allow the Department to create new initiatives in a number of areas that are important to the development of nuclear energy. Even the recent report of the President's Committee of Advisors on Science and Technology is too limited in its recommendations, especially with regard to nuclear energy policy on fuel cycles, and thus falls short of a broad- based vision for nuclear energy. The Department of Energy must establish a strong nuclear energy leadership and advocacy role to bring nuclear energy more equally into the mix of energy systems that are needed for the future. The gradual weakening of the Department's leadership and advocacy role has allowed nuclear energy to be strongly influenced by each changing administration of the government. Finally, the long-term stability and expertise of the Department's management and staff has fallen to a level where it cannot be expected to lead a new, broad-based mission successfully. Steps must be taken to recruit and develop long-term executive management and career staff in the area of nuclear energy-personnel who have the expertise to help define and conduct a broad-based mission, who can effectively undertake public outreach, and who can expect to take long-term accountability for their programs.

Creating a new, broad-based mission will be difficult. The Forum recommends that Congress direct the Department of Energy to create this mission, possibly using experts from outside the Department of Energy for the assignment. This group of experts may take the form of a longterm advisory committee, augmented by facilitated groups who can debate specific aspects of the broader mission and its plans. These groups should draw from leaders and experts within the nuclear industry, nuclear utilities, academia and the national laboratories. 


\section{Action 2}

Congress should direct and immediately fund the construction of a monitored retrievable spent fuel storage facility.

The problem of spent fuel storage and waste disposal stems from a variety of causes and has led to a number of significant challenges for nuclear energy. The lack of political support for a permanent repository and the difficulty of proving its satisfactory performance for ten thousand years or longer makes opening a repository difficult, perhaps even impossible. The resulting lack of progress has confused the public and gives the impression that nuclear fuel cannot be stored safely. These factors in turn provide a focus for antinuclear groups to oppose nuclear power. The inability to open a permanent repository has also jeopardized the continued operation of a number of nuclear power plants where on-site fuel storage is nearing its capacity. This has resulted in several utilities filing lawsuits against the Department of Energy to require that it meet its contractual obligation to remove spent fuel from the reactor sites and to recover added costs resulting from temporary storage.

The Forum strongly voiced that monitored retrievable storage is a realistic option that would allow time for political, social and technical issues to be resolved. A monitored retrievable storage facility would (1) enable the option for future use of material in the spent fuel, (2) contribute to the science of spent fuel storage by establishing fuel and repository performance over long time scales, and (3) would allow due consideration of alternative fuel management schemes to meet future needs and standards. It would also bring U.S. policy in line with policies of other nations, providing an important basis to cooperate internationally on approaches to spent fuel storage and waste disposal. Strengthened international cooperation would enhance U.S. leadership in these issues.

The Forum believes that the attempts made to include interim storage at the Yucca Mountain site have not been successful for political reasons. Given the important benefits and options offered by monitored retrievable storage, the Forum strongly recommends that Congress act to overcome these obstacles with a new initiative on spent fuel storage. 


\section{Action 3}

Congress should support a comprehensive program to secure all weapons grade plutonium and highly enriched uranium, to expand the purchase of vulnerable highly enriched uranium and to undertake a Russian "nuclear cities" initiative.

The security of nuclear materials in Russia and the former Soviet Union represents one of the greatest security threats to the U.S. and the world. The Forum recommends that a comprehensive program to address this threat be supported by the Congress. The U.S. is strongly encouraged to support a rigorous materials protection, control, and accountability system in the military and civilian nuclear complex of Russia and the former Soviet Union. The current program funding of $\$ 137 \mathrm{M}$ in Congress to support this is a crucial first step and must be supported.

The Forum proposes that the U.S. concurrently expand bilateral interactions with Russia and the other states of the former Soviet Union to make changes that will result in a sustainable materials protection, control, and accountability program. A sustainable program is one that Russia will support after U.S. financial support ends, and which they accept as a prerequisite for the conduct of international nuclear trade. One of the most important aspects of building a sustainable safeguards system is to bring stability to the lives of the custodians of nuclear materials. This can be accomplished by an initiative to diversify the economies of Russian nuclear cities and dramatically downsize the military programs. A comprehensive program must include:

- Consideration of the need to maintain adequate Russian military stewardship.

- Consideration of the need to increase nonmilitary nuclear missions significantly in areas of environmental cleanup, materials security, nuclear materials disposition and nuclear power.

- Diversification of economies of these cities, and
- Transformation of social structures and economics systems away from military objectives

A specific action that is encouraged by the Forum is an expansion of the present effort to purchase highly enriched uranium from the Russians. The most vulnerable highly enriched uranium is believed to be in their naval program and in the research reactor programs of Russia and the former Soviet Union.

A final area of recommendations by the Forum concerns reductions in the stockpiles of nuclear materials of the U.S. and Russia. These reductions are important for arms control and nuclear nonproliferation, and reductions should be carried out within the context of the overall U.S. arms control strategy. U.S. actions for reduction of nuclear materials should be driven to achieve parity of weapons-usable materials inventories, much as the Strategic Arms Reduction Treaty is driven by parity in delivery systems and missiles. The earlier highly enriched uranium purchase is a very positive step in this direction, and the plutonium disposition program must be similarly framed. To this end, the Administration is encouraged to develop a new dialog with Russia based on parity and how to attain it. Such a plan should actively drive the next steps in disposition, especially the level of U.S. support for the Russian disposition effort. The disposition efforts should be strongly linked to the materials security efforts and the nuclear cities initiative. The U.S. decision to take both plutonium burning and geologic disposal approaches to weapons grade plutonium disposition are endorsed, and both approaches should be actively pursued. Eventually these efforts must be followed by parallel efforts to achieve parity in production capacity. 


\section{Action 4}

Congress should direct that the nuclear regulatory process be reformed to produce a more efficient, less costly, risk- and performance-based regulatory oversight process.

The Forum finds that the cost of regulation by the Nuclear Regulatory Commission (NRC) imposes a major economic burden on the U.S. nuclear industry. This cost includes both license fees paid to the NRC and the cost of responding to regulatory actions required by the NRC. Underlying any regulatory reform is the fact that continued safe operation of U.S. nuclear power plants is a prerequisite to any future renewal of nuclear energy or license extension of the existing plants. In that regard, the Forum agreed that a high-integrity regulatory process is essential to maintaining public confidence in the safety of nuclear power. More efficient and effective regulation is sought, not necessarily deregulation-the term 'reregulation' is suggested in place of deregulation. The vision for a reregulated environment is one where NRC regulates safety performance against specific, objective, and risk-based performance standards, rather than against a subjective 'regulatory significance' concept. The appropriate role for NRC is viewed, at least by some, as one of performance oversight rather than directing and monitoring the processes employed by the licensee to achieve that performance. The Plenary address by NRC Commissioner Diaz demonstrated a recognition of these issues and an openness to regulatory change that suggests the time is ripe for regulatory reform now.

The Forum specifically recommends that a special task force of senior NRC and industry management be convened this year at the direction of Congress, to develop the scope, schedule and standards for regulatory reform. Industry should be tasked to bring a consensus set of proposed performance measures for regulatory oversight to the task force for discussion, modification, and agreement. The final areas of agreement and disagreement from the task force deliberations should be reported to Congress for dispute resolution, ratification, and ultimately for the purpose of holding both industry and NRC accountable for progress toward these commitments to regulatory reform.

The Forum suggested that specific regulatory issues and goals be submitted to the task force for consideration and subsequent action. These issues range from adoption of international regulatory standards with regulation by an international body to specific changes in U.S. regulatory practices. An immediate need is to assure a predictable costeffective license renewal process. In the long term, the Forum suggests that nuclear plant license terms not be set for a fixed period of time. Rather, the licensee would monitor and manage the aging and safety condition of the plant under the oversight of NRC, such that the plant operating license would be continuously extended. This is similar to the process employed successfully in Europe. The plant operating license would terminate when the licensee could no longer provide evidence justifying assured future safe operation, or when the licensee chose to terminate plant operation for economic or other reasons. Three additional suggestions are recommended for inclusion in the regulatory reform task force deliberations: (1) adjudicatory and enforcement process problems, (2) lack of a firm schedule and process closure commitment from NRC for license renewal actions, and (3) lack of timeliness in spent fuel license reviews. 


\section{Action 5}

The Department of Energy should study the full-cycle economic and environmental costs of energy options, and Congress should legislate a level playing field for all energy sources, including nuclear energy.

The Department of Energy recognizes that a mixed portfolio of energy systems and sources has a great value to the assurance of adequate supplies of environmentally clean energy, reducing the U.S. vulnerability to supply disruptions, encouraging efficiency and developing advanced alternative and renewable energy technologies. The Forum feels, however, that the full-cycle economic and environmental costs of energy options must be better understood in order to assure an appropriate mix. Further, from such an understanding, the Congress should take action to balance the energy portfolio through legislation.

The Forum recognizes that a number of similar studies have been undertaken in the past. To be effective, a new study would critically need to establish credibility and balance the perspectives of its experts, use a clear and consistent methodology, and be quantified to the highest extent possible. However, there were reservations about the ability to achieve this. Options were discussed for having the study conducted or reviewed by the National Academy of Sciences or other expert groups. If successful, such a study would be a significant step toward improving the National Energy Strategy.

While the Forum recommends action for Congress to level the playing field according to full-cycle economic and environmental costs, there was considerable debate over the particular mechanism that should accomplish this. A number of options were identified, including energy use set-asides, incentives and tax credits, and new taxes on energy use or carbon emissions. The set-asides, incentives, or credits were felt to have less potential for political backlash, especially when made part of an overall action to assure an energy portfolio that has an increased emphasis on environmentally beneficial energy sources. 


\section{Action 6}

Congress and the Administration should increase the budget of the Nuclear Energy Research Initiative (NERI) and Nuclear Energy Plant Optimization (NEPO) programs, and Department of Energy should provide sharper focus to the NERI program.

The technical roots for the revitalization of nuclear energy, and for the continued U.S. capability to deal with national and international nuclear issues, are grounded in a system that includes a healthy educational infrastructure, especially at the university level, and a robust research and development enterprise that includes research and development (R\&D) in industry and at universities and national laboratories where the nation's nuclear facilities and infrastructure are maintained. These roots have been severely undernourished in recent years as a result of a general malaise surrounding career futures in nuclear energy, a real loss of jobs and job opportunities, a loss of intellectual curiosity and interest in exploring new nuclear energy technologies, as well as the virtual absence of any Department of Energy (DOE) R\&D programs in nuclear energy at the national laboratories and universities. The new technical talent advancing through the universities into employment in industry and national laboratories is declining. Left unchecked, this trend will destroy the U.S. nuclear technology capability from within.

The DOE Office of Nuclear Energy, Science and Technology has proposed two new nuclear energy R\&D programs to be initiated in FY-1999. These new programs are the Nuclear Energy Research Initiative (NERI) and the Nuclear Energy Plant Optimization (NEPO) programs. The Forum strongly endorses starting the NERI and NEPO programs in FY-1999 at the Senate and Administration budget level of $\$ 24 \mathrm{M}$ and $\$ 10 \mathrm{M}$, respectively. The NERI and NEPO budgets should be increased in FY-2000 to at least double these levels. Ultimately, nuclear energy R\&D should be funded by the Department at a level compara- ble with other major energy sources (\$200-300M/ year).

The Forum recommends sharper focus, betterdefined structure and clearer goals for the NERI program, especially towards the relevance of the research to industry needs, the need for DOE and NRC to cooperate more closely in their R\&D programs, and the need for the DOE Nuclear Energy R\&D program to be better integrated with the Department's Energy Research and other R\&D programs. The Forum concurs with DOE's efforts to anchor the NERI program in merit-based, peerreviewed R\&D. This should include international collaborations and advanced reactor technologies that would make new nuclear plants competitive in a deregulated market place. It is expected that ideas initially explored in NERI would become directly funded DOE programs at the development and testing stage. The Forum made only general recommendations about how to improve the focus and structure of the NERI program. A desire for stronger technology-needs program guidance from DOE and more emphasis on integrated research teams was discussed. Analogies have been drawn between the NERI program and the DOE Environmental Management Science Program; the Forum specifically cautions against this since the Science Program is conducted in an environment where millions of dollars are spent on research that supports large environmental projects elsewhere in DOE, whereas the NERI program has to carry essentially all of the nuclear energy R\&D responsibility itself. Therefore, the Forum feels that the NERI research must be more integrated and directed than the Environmental Management Science Program. 


\section{Action 7}

The Department of Energy should create and fund a viable international reactor technology development program that reduces the threat from weapons plutonium and also encourages the use of new and existing reactors to burn weapons plutonium.

Effective management of weapons grade plutonium involves two distinct actions: (1) securing the present material, and (2) burning it in a reactor system to reduce the inventory and attractiveness of the material. The most immediate need is securing the present material, involving the destruction of weapons and configuring the contained plutonium for safe storage. The next step in the process, as recommended by the Department of Energy and supported by National Academy reviews, is to render the plutonium no more accessible for weapons than plutonium contained in spent commercial fuel.

The Forum recognizes that there is an existing program to use current U.S. and foreign reactors involving partially burning the plutonium as MOX fuel. An alternative aspect of the program entails adding fission products directly as part of program of immobilization in a waste form for disposal. This program is useful in the near term and provides a base to take steps toward a more optimal solution.

The Forum proposes U.S. participation in an international program of reactor technology development that is aimed at burning weaponsgrade plutonium and achieving the acceptance and development of recycle. Such a program would enhance the U.S. leadership role in ensuring nonproliferation and in the development of new reactor technologies. These advanced designs could further reduce proliferation risks, minimize their waste streams, and improve their economics and safety.

Pursuing such an integrated approach in the U.S. and other nations would contribute to the long term energy needs. It would also serve to enhance the viability of a geologic repository by reducing or removing the long-lived actinides from the waste to be stored. However, effective utilization of plutonium for energy production involves recycle-an approach favored by other nations, but which is against U.S. policy.

This action is consistent with the desire to take positive early steps to secure weapons plutonium. The Forum observes that this initiative could begin with an international design study by the principal nations involved in nuclear power development, i.e., the U.S., France, Russia, and Japan. 


\section{Action 8 \\ The Department of Energy should increase public understanding of energy pro- duction and nuclear technology.}

The forum defines two categories of approaches to this problem: approaches that educate the general public about energy and nuclear technology, and approaches that create a national dialogue about energy and nuclear technology.

The Forum feels that an education program is needed to re-educate the public about energy overall. Such a program would require a long term commitment similar in scope and quality to what the National Aeronautics and Space Administration has done. The Department of Energy would function as the leader for advocacy that would include industry and other public and private concerns. The program would need to improve the level of knowledge and understanding, including the benefits and risks of nuclear energy and its technology. The program would be served best by reaching all levels of education and placing added emphasis on teacher education. It was noted that national laboratories such as Oak Ridge National Laboratory have experience with educational programs that reach schools successfully. Funding was also raised as a concern, and it was suggested that funding must come from the stakeholders including the government and industry.

With regard to national dialogue, the Forum also discussed the need to improve public attitudes about radiation safety and nuclear energy. It is important to win over both the general public and the opponents of nuclear energy, resolving differ- ences through dialogue. This dialogue is envisioned as a matter of engagement as opposed to stating positions. All stakeholders at the community and state levels need to be involved in this process, and community acceptance will result from a dialogue that changes beliefs. It was also suggested that while dialogue is necessary, it is important to question opposing groups about inconsistencies in their positions being both proenvironmental and anti-nuclear. It was also suggested that meetings with environmental leaders to discuss how they would propose to meet Kyoto standards would be a good way to engage them regarding an appropriate role for nuclear energy. Some participants believed that if the environmentalists were engaged in a scientific dialogue about the environmental effects of energy sources, some of them would ultimately convince themselves about the benefits of nuclear energy.

There were conflicting views in the Forum regarding where the most attention should be focused. This included suggestions that we should not spend the majority of the efforts on the determined opposition of a minority. This minority is difficult to win over, yet the fact is that even a small minority can stop nuclear power plants and other major projects. In contrast, others suggested that the proponents of nuclear energy really need to listen to environmentalists' issues and concerns, respect the environmental leaders who are opinion leaders, and convince them that nuclear power can operate safely. 


\section{Action 9}

\section{Congress should fund increased research to resolve the health issues of low level radiation exposure to humans.}

The Forum supports the need to conduct comprehensive research that can resolve the controversy about the effects of low level radiation exposure on human health. Substantially increased levels of research are needed to gain a better understanding of the effects of low level radiation on human health. Ultimately, this could alleviate or even eliminate concerns regarding exposure. If this issue were resolved, it would eliminate the use of collective dose for risk assessment and greatly reduce the burden of regulation under uncertainty.

However, concerns were raised that it will take years to produce the answer to this question. It was recognized that research of this nature will be costly, and may in fact be inconclusive.

It was noted that some work in this area is ongoing, including an effort conducted by the National Academy of Science to evaluate the linear no-threshold model. This effort is being funded by the Environmental Protection Agency. It was proposed that additional funding may hasten the research, but it was emphasized that we must let the scientific process work. The answer to the question cannot be mandated, but must follow the scientific process of research, review, and confirmation.

\section{Action 10}

\section{Congress should consider establishing a joint committee on nuclear energy.}

There are 22 committees, subcommittees, and government agencies that oversee various aspects of nuclear-energy-related activities. In support of this action, the Forum reasons that a more focused and more efficient congressional oversight process would better serve nuclear energy.

Standing in opposition to this action is the observation that distributed power in a democracy is better, and that multiple committees may shield nuclear energy from extreme perspectives, pro or con. For example, a single committee that is headed by an individual with opposing views or interests would have a very negative impact on nuclear energy.

Compromise positions were considered by the Forum. For example, it may be advisable to convene a smaller representative group from the committees, thereby improving the communication and decision-making process. Alternatively, it may be advisable to combine functions of the committees such that the total number of committees is much less than the current level. 


\section{THE CURRENT STATE}

Elements of the current state frequently identified by the Forum participants included the following:

- The current state is one where nuclear technology suffers from a high degree of uncertainty, driven by economic and political conditions and by a lack of leadership by the Government to set a course of action for the future in the nation's interest.

- The Government vision expressed in the Comprehensive National Energy Strategy is politicized, lacks a firm technical basis, and results in a failure to lead and advocate nuclear energy.

- International influence in nuclear matters continues to decline.

- Progress toward a solution to the nation's nuclear waste issue remains stifled by political maneuvering, and the public is led to view the waste issue as unsolvable.

- A major threat from the lack of security of the nuclear materials in the former Soviet Union is not adequately recognized nor dealt with decisively by the Administration.

- There is no comprehensive integrated approach in the Department of Energy to nuclear materials management, and the fuel cycle continues to be constrained by administration policy.

- The nuclear regulatory process in the U.S. has failed to mature with the industry. It is too expensive, regulatory standards are too subjective, and regulatory responses are too pejorative.

- The future competitiveness of the nuclear power industry is at serious risk as it faces economic deregulation of the electricity market with the economic scales tipped unfairly against it. Nuclear power, unlike its fossil-fueled counterparts, pays directly for its regulatory system and for the disposal of its waste - both of these place an economic burden on the industry that is not borne by its competitors.

- The once preeminent U.S. nuclear technology base is aging, the number of scientists and engineers is declining, and the physical and personnel infrastructure at our universities and laboratories is deteriorating such that we will not sustain technological leadership in the future.

- The U.S. lacks a comprehensive nuclear technology development program, and there has not been a nuclear energy $R \& D$ program of any substantial size or scope at our laboratories or universities for several years.

- The benefits of emission-free nuclear power go unacknowledged by the Government and unrecognized by the public who are left in a vacuum to deal with the controversies of nuclear wastes.

- A vocal minority has exagerated the dangers, exacerbated the fears, and diminished the value of nuclear energy, by using intervention systems designed to foster honest public debate. These disruptive tactics have not been successfully countered by the Government nor by industry nor by the public they harm. 


\section{THE DESIRED FUTURE STATE}

Elements of the desired future state frequently identified by the Forum participants included the following:

- The desired future state must be one of predictability and leadership in the nation's interest. From this leadership will have emerged a science-based national energy policy with a strategy that sets a predictable course of Government actions that allow the nuclear industry to operate effectively.

- Spent nuclear fuels are stored in monitored, retrievable storage facilities, and nuclear wastes are dispositioned safely in licensed repositories.

- The decision to reprocess spent fuel is determined by economic factors rather than political issues.

- International standards are in place for handling weapons materials, including those in the former Soviet Union.

- The stockpiles of weapons material have been reduced to manageable and secure levels.

- The U.S. retains its strong leadership and influence on international nuclear matters, and a new international paradigm is in place to allow nuclear energy and international nuclear material security goals to be met simultaneously.

- Mixed oxide fuel is widely used in the U.S. and throughout the world to extract the maximum energy content from both weapons materials and spent fuel. At the same time, security and nonproliferation issues are effectively dealt with as a part of a comprehensive nuclear materials management program.

- The regulation of nuclear energy by the Nuclear Regulatory Commission is efficiently and effectively based on objective performance- and risk-based standards.

- Nuclear plants continue to operate worldwide with exemplary safety records.

- Nuclear plant licenses for new plants are granted without impacting construction schedules, and licenses for existing plants are routinely extended.

- Nuclear power competes in a deregulated electricity market on a level economic playing field where all energy sources pay their full life-cycle cost, including pollution emission costs.

- Market needs, national security, and environmental needs can all be met simultaneously with newly developed nuclear energy technology. New capacity is being built in the U.S. and around the world.

- The DOE Nuclear Energy R\&D budget is comparable to other energy technologies, and ongoing, state-of-the-art university and laboratory research is complemented by a vital industry R\&D program.

- Young people are attracted to careers in nuclear energy because of the long-term, technically challenging work, and by a sense of pride in nuclear energy and nuclear technology that serves mankind's energy, medical, diagnostic and food safety needs.

- Environmental leaders support nuclear energy, and the public is both informed and knowledgeable about the benefits and risks of nuclear energy.

- Special-interest anti-nuclear groups no longer command the attention of the media, and they are therefore less effective at disrupting decisions that are in the national interest. The public is informed, knowledgeable, and engaged in nuclear issues, and is better served by the media.

- Human health effects of low levels of radiation have been studied and understood by scientists, and the linear dose extrapolation model has been scientifically discredited. This allows nuclear operations and environmental cleanup to be conducted cost-effectively to science-based standards. 


\section{THE FORUM PROCESS}

The Decision-Makers' Forum on a New Paradigm for Nuclear Energy was held on June 19, 1998 in Washington DC. Sponsored by the Senate Nuclear Issues Caucus, the Forum was organized and facilitated by the Idaho National Engineering and Environmental Laboratory. The day consisted of two events. First, a two-hour plenary session was addressed by Sen. Pete V. Domenici (R-NM), Rep. Joe Knollenberg (R-MI), Nuclear Regulatory Commissioner Nils Diaz, Undersecretary of Energy Dr. Ernie Moniz, and Dr. Vic Reis and Mr. Bill Magwood, heads of Defense Programs and Nuclear Energy for the Department of Energy, respectively. Second, the 60 participants divided into three breakout sessions for the balance of the day. The participants were decisionmakers and key staff from industry, government, the national laboratories, academia and professional societies. The breakout sessions were organized into three themes: (1) Revitalizing Nuclear Energy, (2) Global Nuclear Materials Management, and (3) Advanced Nuclear Systems and Fuel Cycles.

While the three breakout sessions had unique themes, all were facilitated in the same way. Each participant could use a personal computer to capture ideas and comments anonymously into the session record. For some phases of activity, the facilitators would display group ideas or statistics on the networked computers for all participants to view. The GroupSystems ${ }^{\circledR}$ software from Ventana Systems, Inc. was resident on each computer and on a server operated by a technographer who assisted with archiving responses and displaying results. The sessions would also include time for jointly brainstorming and discussing ideas as a group. During these times the technographer would simultaneously transcribe ideas and display them on each computer for all to view. Each session was guided by a professional facilitator, skilled in leading discussion, and a session leader, expert in the subject matter.

The roughly 20 participants in each session worked for about 90 minutes to characterize the current state of affairs, then another 90 minutes to define elements of the desired future state. The purposes of this activity were to introduce the participants to the system and to set a common understanding of the differences, or tensions, between current and desired states. Following this, the participants brainstormed actions and debated them for about an hour. After dozens of actions were identified, the participants began a series of votes to establish those with majority support. The voting served to identify about five to ten high priority actions. Following this, the participants continued to comment on these priority actions in order to identify critical issues, barriers and opportunities for achieving them. Toward the end of the day, after about six hours of discussion and reflection, the session leaders produced a summary of the day's results. All participants reconvened for a half-hour closing plenary session to hear a brief summary by each of the three session leaders.

The Forum produced about 100 pages of ideas, comments and tabulations of votes captured in a Forum Record, with about five to ten priority actions from each breakout session. The three session leaders then took up editing and writing this report. All began by reading and working with the entire Forum Record. The editorial team met repeatedly to merge similar actions and to weigh the overall ranking of each. This resulted in a consolidated set of ten priority actions from the Forum. The editors then wrote descriptions of the actions, as well as the background sections for the Forum Report.

When finished, the draft Forum Report and Forum Record were made available to all participants on the Internet, and a comment period was held. The editorial team met to consider and resolve each comment on the Report-individual participants were not allowed to directly input changes, but they were allowed to send additional comments and reflections to be appended to the Record. Overall, the Forum was designed to capture the ideas of a large number of decision-makers about the high priority actions recommended to help set a new national agenda for nuclear energy. 


\section{FORUM PARTICIPANTS}

\section{Session I \\ Revitalizing Nuclear Energy}

Session Leader:

Dr. Harold Blackman, INEEL

Joe Colvin

Nuclear Energy Institute

Bev Cook

DOE-NE

Nils Diaz

NRC Commissioner

Mike Garbett

Transition Management, Inc.

Mike Golay

MIT

Beverly Hartline

Office of Science and Technology

Policy

Stan Hatcher

American Nuclear Society

Bennett Johnston

U.S. Senate (Ret.)

Andy Kadak

American Nuclear Society

James Lake

INEEL

Pete Lyons

Congressional Staff

Bill Magwood

DOE-NE

Corbin McNeill

PECO Energy Company

Nestor Ortiz

Sandia

Otto Raabe

Health Physics Society

Forrest Remick

USNRC (Ret.)

Kristine Svinicki

Congressional Staff

John Taylor

EPRI (Ret.)

Mike Tuckman

Duke Power

\section{Session II \\ Global Nuclear Materials \\ Management}

Session Leader:

Dr. John Sackett, ANL-W

Matthew Bunn

Harvard University

Howard Canter

DOE-MD

Tom Dabrowski

Waste Management, Inc.

Alex Flint

Congressional Staff

Bob Hanfling

Putnam, Hayes, and Bartlett

Sig Hecker

LANL (Ret.)

Tom Hunter

Sandia

Tom Isaacs

LLNL

Arvid Jensen

INEEL

Nils Johnson

Congressional Staff

Dale Klein

Amarillo National Resource Center

for Plutonium

David Martin

Martin Corporation

Marilyn Meigs

BNFL

Lawrence Scheinman

U.S. Arms Control and Disarmament

Agency

Ted Quinn

American Nuclear Society

Elizabeth Turpen

Congressional Staff

Leon Walters

ANL

\section{Session III \\ Advanced Nuclear Systems \& Fuel Cycles}

Session Leader:

Dr. Ralph Bennett, INEEL

Ed Arthur

LANL

Linden Blue

General Atomics

Jim Cannon

Congressional Staff

Ben Combs

Combs \& Company

George Davis

ABB-Combustion Engineering

John Herczeg

DOE-NE

Karen Hunsicker

Congressional Staff

Mujid Kazimi

MIT

Philip MacDonald

INEEL

Yuichiro Matsuo

Electric Power Companies of Japan

Mike McMurphy

COGEMA

David Rossin

Rossin and Associates

Stan Schriber

LANL

Robert Socolow

Princeton University

Terry Surles

LLNL

Chuck Till

ANL (Ret.)

Bob Vijuk

Westinghouse

Alan Waltar

Texas A\&M University 